\title{
Deflection Analysis of Multi Story Building G+10 in Various Seismic Zones with and Without Base Isolation Using Etabs
}

\author{
K.Santhosh ${ }^{1}$, Y.Mahesh ${ }^{2}$ \\ ${ }^{I}$ (Post Graduate Student, Department of Civil Engineering, VITAM College of Engineering, Visakhapatnam, \\ INDIA) \\ ${ }_{2}^{2}$ (Assistant Professor, Department of Civil Engineering, VITAM College of Engineering, Visakhapatnam, \\ INDIA)
}

\begin{abstract}
The behavior of G+10 multi story building of with and without Base isolator under seismic loads were studied. In this paper a G+10 multi story building of dimensions $18 m * 21.5 \mathrm{~m}$ with each story height of $3.5 \mathrm{~m}$ and total height of the building $38.5 \mathrm{~m}$ is studied for different seismic loads in ETABS. These analyses are carried out by considering different seismic zones and for each zone the displacement is analyzed for different load cases with and without Base isolator. The method includes seismic coefficient method as recommended by IS 1893:2002.
\end{abstract}

Keywords: Seismic loads, Base-Isolator, Displacement Analysis, Lead-Rubber Bearing Isolator.

\subsection{Concept Of Base Isolation:}

\section{Introduction}

The basic concept in seismic isolation is to protect the structure from the damaging effects of an earthquake by introducing a flexible support isolating the building from the shaking ground. In the literal sense, the structure is separated from its foundations. In practice, a full separation of the structure from its foundations is impossible, as large relative horizontal displacements have to be avoided either during the earthquakes or when other horizontal loads such as wind are present. Hence, the common solution is to use a layer, usually between foundation and superstructure, which is more flexible than the other structural elements and is able to transmit the vertical load when undergoing lateral displacements without critical damages.

\subsection{The Procedure For Earthquake Analysis Of The Structures:}

o Linear Static Procedure

- Linear dynamic Procedure o Response Spectrum method o Time history method

- Nonlinear Static Procedure (Pushover analysis) o Nonlinear dynamic procedure As per IS-1893:2002,

Methods Adopted are

- Equivalent Static Lateral Force (or) Seismic Coefficient Method

\subsection{Advantages Of Base-Isolation:}

i. Structural damage is restricted when the structure is built on a suitable seismic isolating system.

ii. The base Isolation will protect the structure by preventing plastic deformation of structural elements, because, the super-structure demonstrates elastic behavior during initial and following excitation of the base.

iii. Secondary damage and injury as a result of falling furniture would be restricted

iv. The function of buildings can be ensured during an excitation or even after a major earthquake as superstructure is designed to remain elastic

v. Reduction in earthquake input forces, could lead to slender structural elements and consequently the considerable reduction in the whole weight of structure, which gives the noteworthy reduction in construction materials and construction costs.

vi. Considerable safety improvements would reduce disaster management protocol for such buildings during an earthquake and reduction of repair costs after an earthquake, seismic isolation can reduce life cycle costs.

\subsection{Definitions:}

1.4.1 Earthquake: Vibrations of the earth's surface caused by waves coming from a source of disturbances inside the earth are described s earthquake. By far the most important earthquake from the engineering point of view is of the tectonic origin that is those associated with large scale strains in the earth crust of the earth. One of the theories describing this phenomenon is termed elastic rebound theory. It says that 
the strain energy that accumulates due to deformation in earth mass, gets released is propagated in the form of wave which impact energy to the media through which they pass and vibrate the structure standing on the earth's surface.

1.4.2 Base-Isolator: It is a technique to prevent building during an earthquake. A fixed-base building (built directly on the ground) will move with an earthquake's motion and can sustain extensive damage as a result. Base isolators work in a similar way like car suspension. It is not suitable for all types of structures and is designed for hard soil, not soft soil.

\subsubsection{Types of Base-Isolator:}

1.4.3.1 Sliding Systems: Sliding systems are simple in concept and have a theoretical appeal. A layer with a defined coefficient of friction will limit the acceleration to this value and the forces which can be transmitted will also be limited to the coefficient of friction times the weight.

1.4.3.2 Elastomeric Rubber Bearings: Elastomeric bearings are formed of horizontal layers of natural or synthetic rubber in thin layers bonded between steel plates. The steel plates prevent the rubber layers from bulging and so the bearing is able to support higher vertical loads with only small deformations. Under a lateral load the bearing is flexible.

1.4.3.3 Springs: There are some proprietary devices based on steel springs but they are not widely used and their most likely application is for machinery isolation. The main drawback with springs is that most are flexible in both the vertical and lateral directions. The vertical flexibility will allow a pitching mode of response to occur. Springs alone have little damping and will move excessively under service loads.

1.4.3.4 Rollers and Ball Bearings: Rolling devices include cylindrical rollers and ball races. As foe springs, they are most commonly used for machinery applications. Depending on the material of the roller or ball bearing the resistance to movement may be sufficient to resist service load resistance and so are used in parallel with other devices to provide these functions.

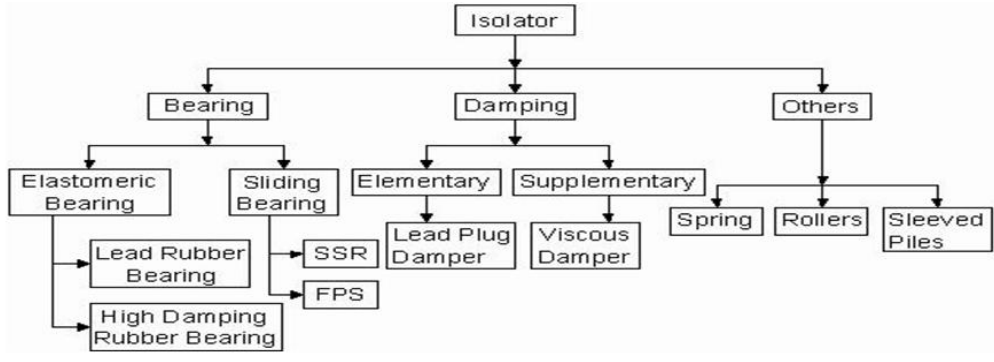

\subsection{Literature Review:}

1.5.1 Prof.R.B.Ghodke, Dr.S.V.Admane,

"Effect Of Base-Isolation For Building Structures", International Journal of Science, Engineering and Technology Research (IJSETR) Volume 4, Issue 4, April 2015. The result gives the study and the importance of keeping the superstructure stable while the foundation is being shaken by an earthquake. So important is that to design a system that puts these concepts into practice. The study results the Increases with height of building displacement is decreases for base-isolated building and increases with height of building displacement is also increases for fixed base building. By result obtained for displacement is less with base - isolation as compared to fixed base.

\subsubsection{Evany Nithya S., Dr. Rajesh Prasanna P,}

Studied that using rubber elastomer for base isolation, it is possible to avoid large plastic deformation of moment resisting frame and reduce shear resulting from large scale earthquake. This study shows that there may be significant application potential for non-linear semi-active devices in structural isolation . 


\section{Plan, Elevation And Structural Properties of Building}

2.1 Plan and Elevation:

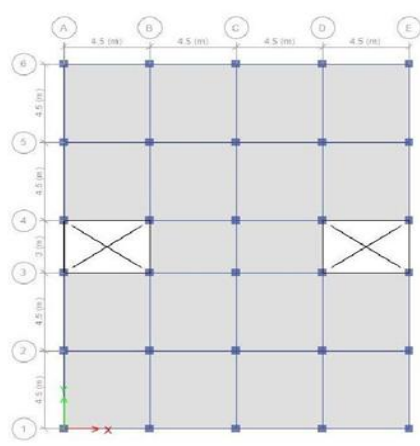

Fig: 1 Plan

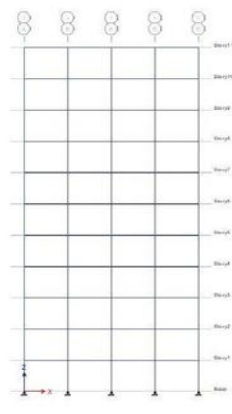

Fig:2 Elevation

\subsection{Structural Properties:}

\subsubsection{Dimensions:}

Columns : $0.45 \mathrm{~m} \times 0.45 \mathrm{~m}$ Beams : $0.25 \mathrm{~m} \times 0.45 \mathrm{~m}$

Slab : 150mm Area: 378 sq. m Concrete : M30

\subsubsection{Loads:}

Self weight $=$ slab + column + beams + walls

Live load $=4 \mathrm{k}-\mathrm{N} / \mathrm{m}^{2}$

Seismic $(\mathrm{X} \& \mathrm{Y})=$ zone-II, zone-III, zone-IV, and zone-V

\subsubsection{Load combinations:}

$1.5(\mathrm{DL}+\mathrm{EQ}-\mathrm{X}) 1.5(\mathrm{DL}+\mathrm{EQ}-\mathrm{Y})$

$1.2(\mathrm{DL}+\mathrm{LL}+\mathrm{EQ}-\mathrm{X}) 1.2(\mathrm{DL}+\mathrm{LL}+\mathrm{EQ}-\mathrm{Y}) 0.9 \mathrm{DL}+1.5 \mathrm{EQ}-\mathrm{X}$

$0.9 \mathrm{DL}+1.5 \mathrm{EQ}-\mathrm{Y}$

\subsection{Dimensions:}

\section{Design of Base-Isolator}

\begin{tabular}{|c|c|c|}
\hline ITEM & SYMBOL & VALUE(in $\mathrm{mm}, \mathrm{kN}$ ) \\
\hline Diameter of rubber in the is olator & Di & $405 \mathrm{~mm}$ \\
\hline Height of the isolator & $\mathrm{H}$ & $300 \mathrm{~mm}$ \\
\hline No. of Layers in the isolator & $\mathrm{N}$ & 20 \\
\hline Diameter of the Lead in the isolator & D1 & $100 \mathrm{~mm}$ \\
\hline Max displacement & D max. & $200 \mathrm{~mm}$ \\
\hline Axial load capacity & $P$ max. & $900 \mathrm{kN}$ \\
\hline Mild steel plate thickness & & $2 \mathrm{~mm}$ \\
\hline Mild steel plate layers & & 19 \\
\hline Rubber thickness & & $13.1 \mathrm{~mm}$ \\
\hline Total rubber thickness & & $262 \mathrm{~mm}$ \\
\hline Structure damping & B & $5 \%$ \\
\hline Rubbercover & & $20 \mathrm{~mm}$ \\
\hline Effective rubber dia. (cover) & $\mathrm{De}$ & $365 \mathrm{~mm}$ \\
\hline
\end{tabular}

\subsection{Design Steps Of Base-Isolator:}

3.2.1 Characteristic Strength: $Q_{D}=A_{P L} * L_{Y S}=62.83185307$

Where Apl $=$ area of plug $=128824.9 \mathrm{~mm}^{2}$, Lys $=$ lead yield strength $=0.008$

3.2.2 Post Yield Strength: $\mathrm{kP}=\mathrm{Gy} *(\mathrm{Ar} / \mathrm{Tr})=0.32320483$

Where $\mathrm{Gy}=$ shear modulus $=0.0007$, Ar $=$ Rubber area $=120971 \mathrm{~mm}^{2}, \operatorname{Tr}=$ Total rubber thickness $=262 \mathrm{~mm}$

3.2.3 Elastic Stiffness: $\mathrm{ke}=10 * \mathrm{kp}=3.23204834$ Where $\mathrm{kp}=$ post yield strength

3.2.4 Yield Displacement: $\mathrm{Dy}=\mathrm{Qd} /(\mathrm{ke}-\mathrm{kp})=21.6002865 \mathrm{~mm}$ 
Where $\mathrm{Qd}=$ Characteristic strength, $\mathrm{kp}=$ post yield strength, ke= Elastic stiffness

3.2.5 Yield Force: $\mathrm{Fy}=\mathrm{Qd}+(\mathrm{kp} * \mathrm{Dy})=68.8131701 \mathrm{kN}$

3.2.6 Maximum Force: $\mathrm{Fm}=\mathrm{Qd}+(\mathrm{kp} * \mathrm{Dm})=127.47282 \mathrm{kN}$

3.2.7 Effective Stiffness: $\mathrm{Keff}=\mathrm{Fm} / \mathrm{Dm}=0.6373641$

3.2.8 Area Of Hysteresis Loop: $\mathrm{Ah}=4 \mathrm{Q}(\mathrm{Dm}-\mathrm{Dy})=44836.7383 \mathrm{~mm}^{2}$

3.2.9 Effective Viscous Damping: $B$ eff $=\mathrm{Ah} / 2 \pi /(\mathrm{Fm} * \mathrm{Dm})=0.2798$

3.2.10 Rotational Stiffness (Moment Of Inertia): $I=\Pi d^{4} / 64=8715.97799 \mathrm{~mm}^{4}$

3.2.11 Post Yield Stress Ratio: Kratio $=\mathrm{kp} / \mathrm{ke}=0.1$

\section{Results And Discussions}

The present study has been concentrated on eleven storied $(\mathrm{G}+10)$ building. The buildings considered have a plan of dimension of $18 \mathrm{~m}$ in length and $21.5 \mathrm{~m}$ width of the building, the plan and elevation of buildings. The height of the each storey is $3.5 \mathrm{~m}$ and a column height of $1.5 \mathrm{~m}$ has been extended below the plinth beams. A solid slab of thickness $150 \mathrm{~mm}$ has been considered for all storey as per IS: 875 part-2-1987, Live load intensity of $4 \mathrm{kN} / \mathrm{m}^{2}$ has been assumed on each storey and roof has been assumed a uniform live load intensity of $1.5 \mathrm{kN} / \mathrm{m}^{2}$. The modeling has been performed by E-TABS software for the seismic Zone-II, Zone-III, Zone-IV, and Zone-V. Grade of Concrete is M30 and for Fe500. The values of various factors have been assumed as per IS: 1893 part-I-2002. The design of members has been carried out as per IS: 456-2000 the beam and column has been design by IS: 456-2000(5). The fixed base and Base isolated building performance point is calculated by using E-TABS software and story drift is for EQ-X and EQ-Y direction is calculated and hinges also form to the structure.

\subsection{Deflections For The Load Case 1.2(DL+LL+EQ-X) For Zone-II:}

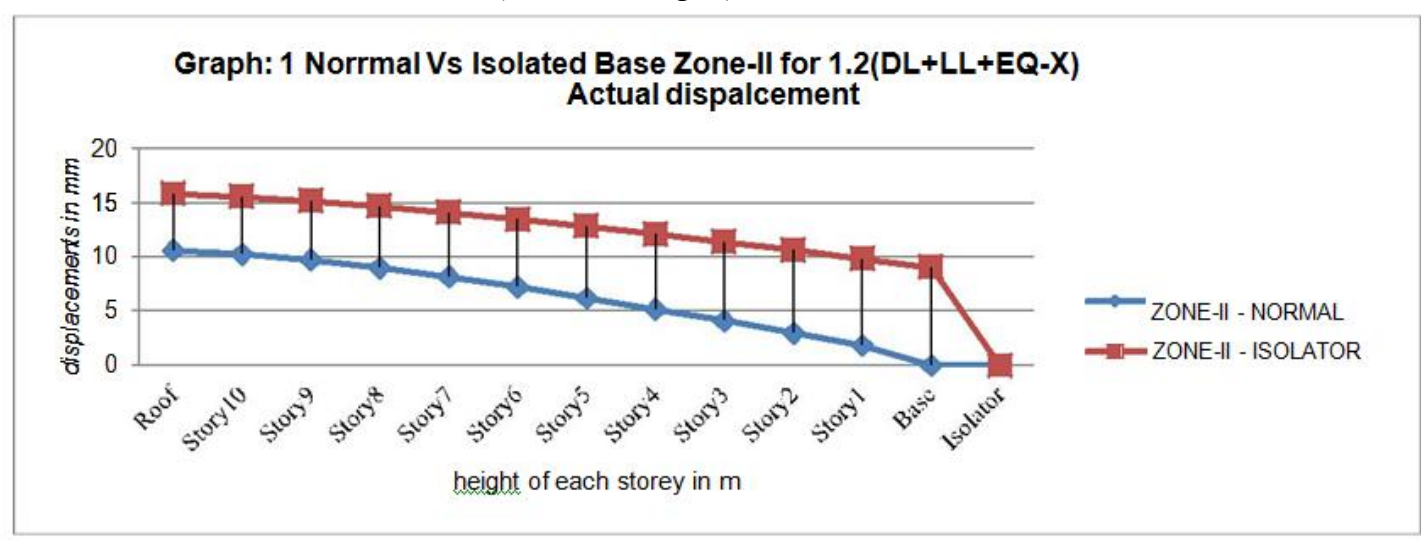

Graph:2 Normal Vs Isolated base-Zone-II for 1.2 ( $D L+L L+E Q-X)$ Relative displacement

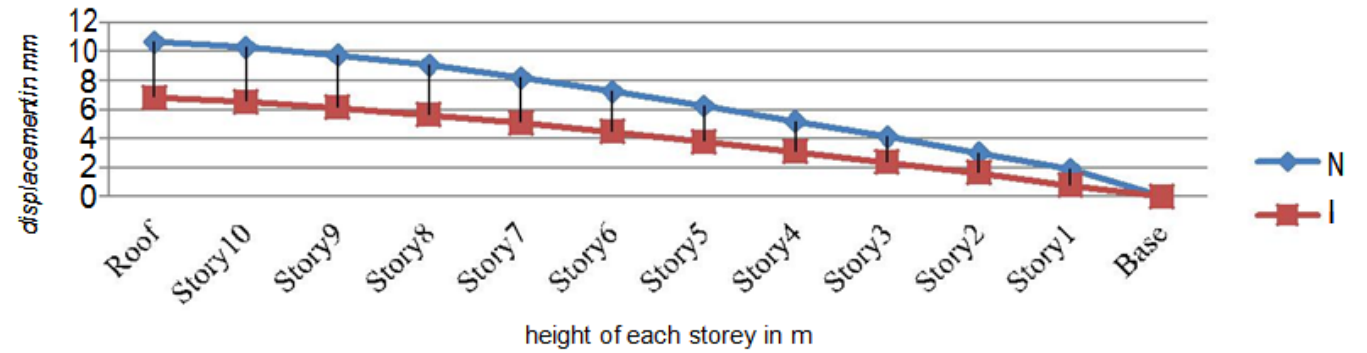

1. From the graph.1 we can see that the actual displacement of the building with the isolator was more compared with without base isolator but when we deduct the displacement of the isolator's.

2. From the graph.2 we can see that the Relative displacement will be reduced for the base isolators building much more than the normal base. 
4.2 Deflections For The Load Case 1.2(DL+LL+EQ-X) for zone-III:
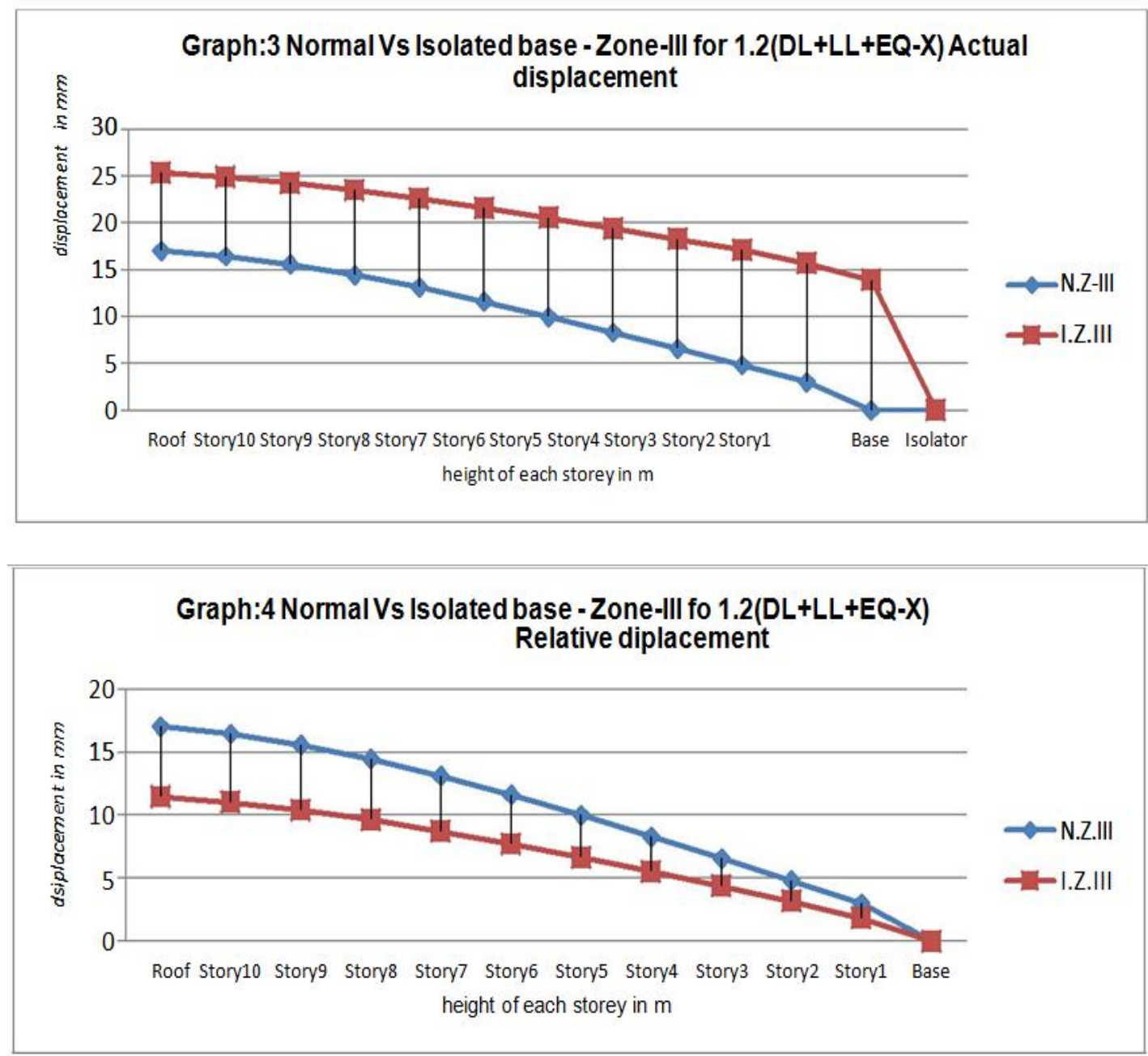

1. From the graph.3 we can see that the actual displacement of the building with the isolator was more compared with without base isolator but when we deduct the displacement of the isolator's.

2. From the graph.4 we can see that the Relative displacement will be reduced for the base isolators building much more than the normal base.

4.3 Deflections For The Load Case 1.2(DL+LL+EQ-X) For Zone-IV:

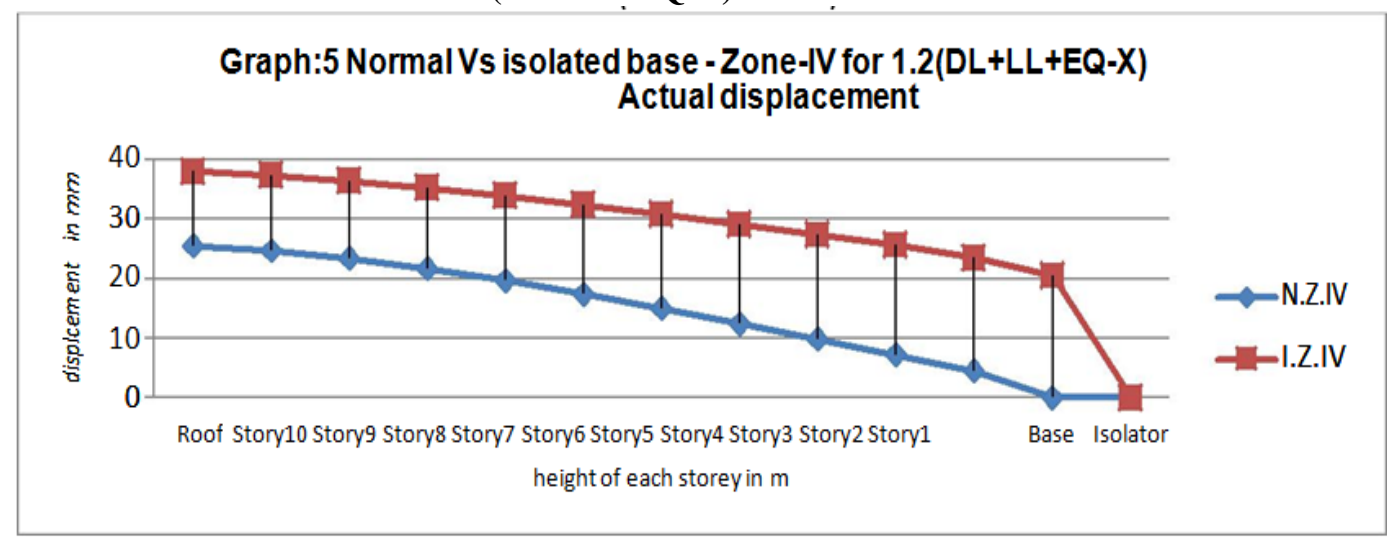

1. From the graph.5 we can see that the actual displacement of the building with the isolator was more compared with without base isolator but when we deduct the displacement of the isolator's.

2. From the graph.6 we can see that the Relative displacement will be reduced for the base isolators building much more than the normal base. 
4.4 Deflections For The Load Case 1.2(DL+LL+EQ-X) For Zone-V:
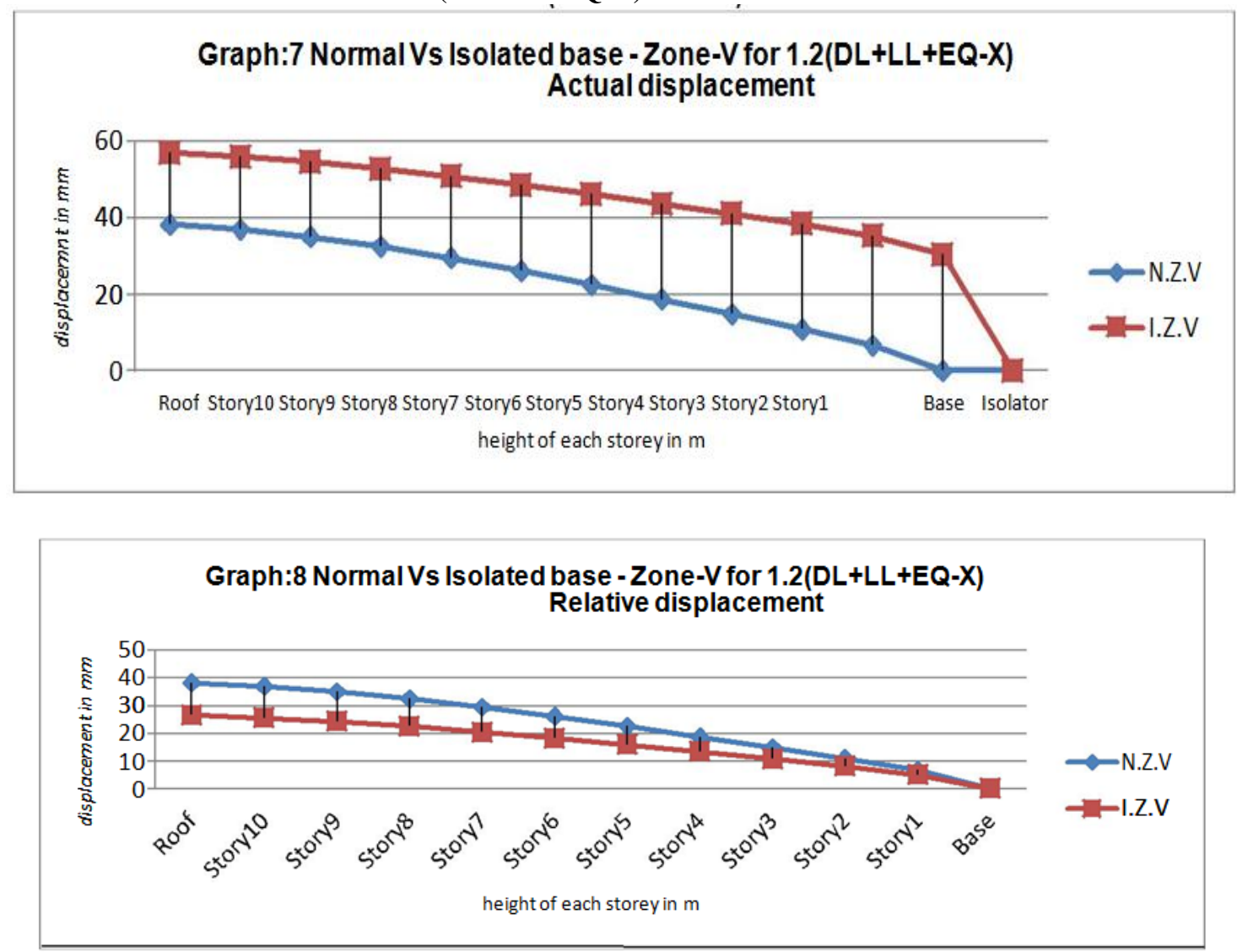

1. From the graph.7 we can see that the actual displacement of the building with the isolator was more compared with without base isolator but when we deduct the displacement of the isolator's.

2. From the graph.8 we can see that the Relative displacement will be reduced for the base isolators building much more than the normal base.

4.5 Deflections For The Load Case 1.2(DL+LL+EQ-X) For Zone:

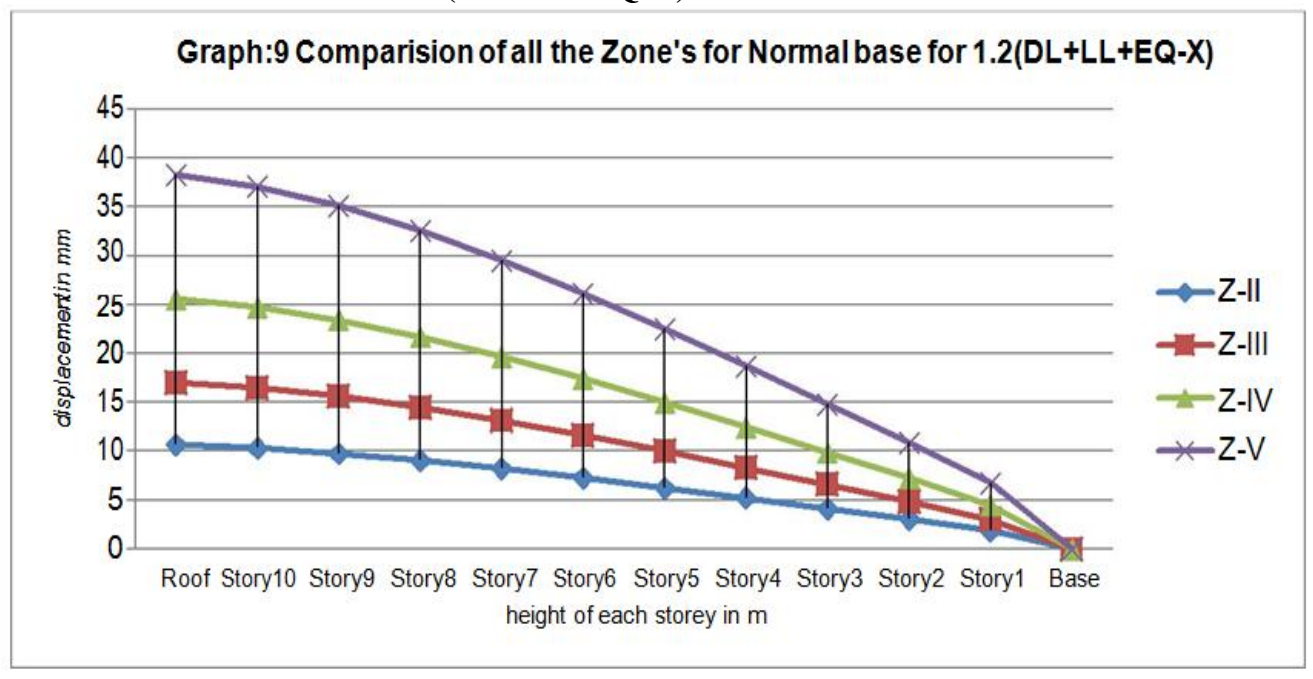




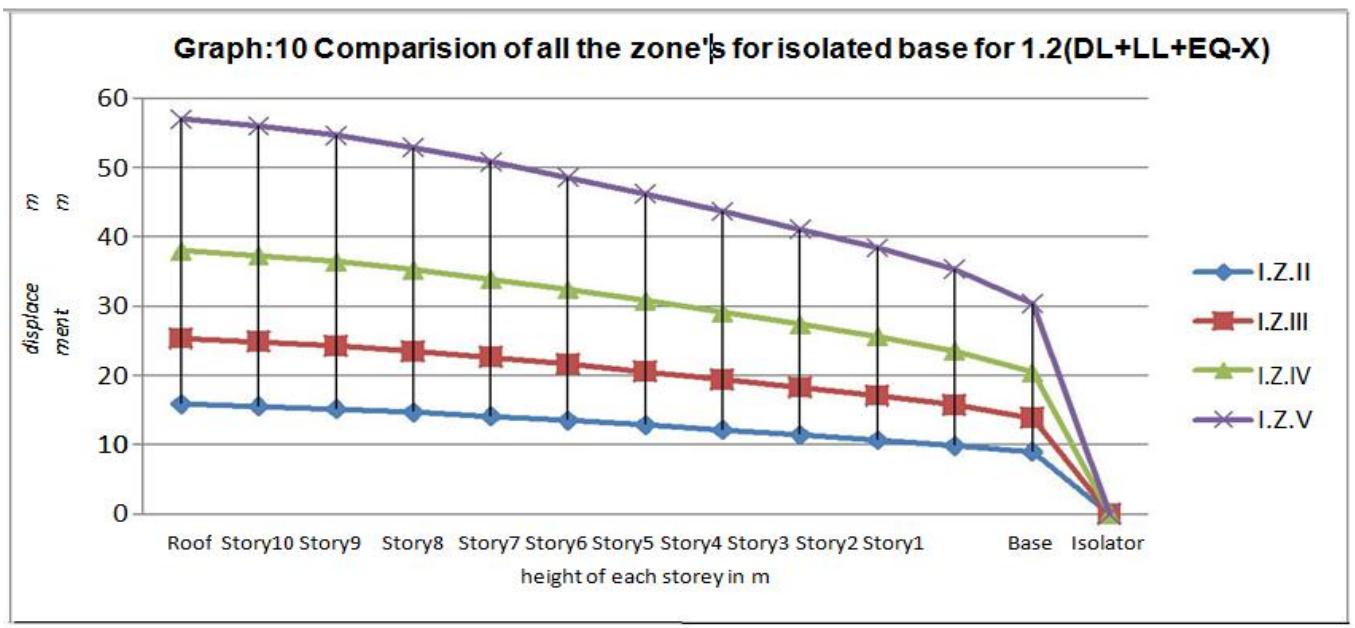

1. From the above graph.9 we can say that the displacement for normal base for Zone-II is minimum when compared to Zone-V. So for Zone-V I recommend for better to install a Base-Isolator to reduce the displacement.

2. From the above Graph.10 we can say that by using by the installing of a Base-isolator we can reduce the relative displacement at Zone-V.

\section{Conclusion}

1. Hence by this method we can reduce the deflection of the building and can make the building safe during earthquakes.

2. It is concluded that increases with height of building displacement is decreases for base-isolated building.

3. It is concluded that increases with height of building displacement is also increases for fixed base building.

4. By result obtained for displacement is less with base -isolation as compared to fixed base.

5. Base isolation systems are adopted in many places in the world but still not much awareness and usage is available in India. In India, this passive technology can be adopted for many structures located in high seismicity zones to make them seismically safe. The damages can be greatly reduced due to the increase of time period resulting in reduced response.

\section{References}

[1]. IS: 456 (2000), Plain and Reinforced Concrete - Code of Practice, Bureau of Indian Standards, New Delhi.

[2]. T. K. Datta Indian Institute of Technology Delhi, India, Seismic analysis of structure.

[3]. IS: 1893 (Part1), Indian standard criteria for earthquake resistant design of structures, 2002

[4]. Uniform Building Code UBC (1997), Chapter 16, Division IV-Earthquake regulations for Seismic-Isolated Structures.

[5]. Prof.R.B.Ghodke, Dr.S.V.Admane, "Effect of Base-Isolation For Building Structures", International Journal of Science, Engineering and Technology Research (IJSETR) Volume 4, Issue 4, April 2015.

[6]. S.Keerthana, "Seismic Response Control Using Base Isolation Strategy" International Journal of Emerging Technology and Advanced Engineering, ISSN 2250-2459, ISO 9001:2008 Certified Journal, Volume 4, Special Issue 4, June 2014) International Conference on Advances in Civil Engineering and Chemistry of Innovative Materials (ACE C IM' 14).

[7]. T. Subramani, "Earthquake Analysis of Structure by Base Isolation Technique in SAP" et al Int. Journal of Engineering Research and Applications, ISSN: 2248-9622, vol.4, issue6(version 5), june 2014. 